\title{
Experimental Research on Creep Function of Offset Blanket in Offset Press
}

\author{
Peng $\operatorname{Liu}^{\mathrm{a}, \mathrm{b}} *$ \\ ${ }^{\text {a }}$ School of Mechanical Engineering; ${ }^{\mathbf{b}}$ Faculty \\ of Printing and Packaging Engineering \\ ${ }^{\mathbf{a}}$ Northwestern Polytechnical University; ${ }^{\mathbf{b}} \mathrm{Xi}$ 'an \\ University of Technology \\ Xi'an, China \\ e-mail: jove.pliu@gmail.com
}

\begin{abstract}
Nanoindentation
experimental technique was used to study the viscoelastic behavior of offset blanket in the paper. And nanoindentation technique is suit to study the mechanical properties and the viscoelastic behavior of flaky materials, very small structures and functionally graded materials. The creep function formula of offset blanket in the experimental situation was induced. We fitted the experimental curves to the creep function formula of offset blanket to find the best-fit parameters. The creep function of offset blanket obtained from this experimental method has contributed to the research on the precise ink transfer rule of offset press. The results show that the computer simulation calculation from the model considered the creep behavior of rubber blanket is more in line with the experimental performance of offset printing machine. So the viscoelastic creep behavior of rubber blanket is very important in getting the precise ink transfer rule in the research of offset press control technology.
\end{abstract}

Keywords-Offset press; Offset blanket; Viscoelasticity; Creep function; Nanoindentation

\section{INTRODUCTION}

In the printing industry, offset printing is in the lead with a share of around 65 to $70 \%$. And

\author{
Linghui Ren \\ Research and Development Department \\ Xi' an Aaerospace-huayang Printing \& \\ Packaging Machinery co., ltd \\ Xi' an, China \\ e-mail:275855433@qq.com
}

the offset press is the most widely used printing
machine in the world ${ }^{[1]}$. The schematic diagram
of offset press is shown in Fig .1.

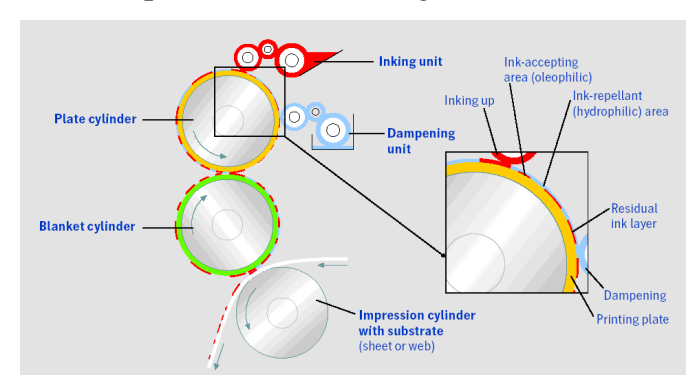

Figure 1. Schematic diagram of offset press

The offset press is composed of such parts: dampening unit, inking unit, plate cylinder, blanket cylinder and impression cylinder. The sheet-shaped plate is mounted on the plate cylinder. And a rubber blanket is also installed on the blanket cylinder. During the printing process, at first the dampening unit transport fountain solution from the solution pan to the plate cylinder, then the inking unit transport ink from the ink fountain to the plate, and the plate cylinder transport the mixture of ink and solution to the blanket cylinder which in succession transfers the image to the paper ${ }^{[2]}$.

In order to guarantee the good quality of printed goods in the color consistency and promote the intellectualized level of offset press, getting the precise ink transfer rule is very important. But this ink transfer rule has not been got because the contact in offset machine belongs 
to viscoelastic contact which is a complex problem ${ }^{[3,4]}$. The viscoelastic behavior of offset blanket got from mechanics experiments will contribute to the research on this viscoelastic contact. And nanoindentation technique is suit to study the mechanical properties and the viscoelastic behavior of flaky materials, very small structures and functionally graded materials ${ }^{[5]}$. In the paper, the creep compliance of offset blanket is measured by nanoindentation for the offset blanket is just a flaky material.

\section{THEORETICAL BACKGROUND}

During nanoindentation, different shaped indenters in fine scale are used to load a sample in a controlled way, while the displacement is continuously recorded. Nanoindentation on a sample material can be considered as a process of indenting a half-space. In this study, the spherical indenter made of diamond is used. Therefore all following formula derivation are based on the spherical shaped indenter.

For linearly elastic indentation problem, Sneddon $^{[6]}$ derived the indentation load-displacement relation by spherical indenter as follows

$$
P=\frac{8 \sqrt{R}}{3(1-v)} G h^{3 / 2}
$$

where $\mathrm{P}$ is the indentation load on a spherical indenter, $\mathrm{R}$ is the radius of the sphere of the spherical indenter, $v$ is the Poisson's ratio, $\mathrm{G}$ is the shear modulus, and $\mathrm{h}$ is the indentation depth of the spherical indenter tip into the sample material.

In the indentation of a rigid indenter to a half-space composed of a linearly viscoelastic material, the contact is a quasi-static boundary value problem with moving boundary between the indenter and the half-space ${ }^{[7]}$. In other words, the contact area between the indenter and the half-space can change with time. To this problem, Lee and $\operatorname{Radok}^{[8]}$ proposed a hereditary integral operator to find the time-dependent stresses and deformations based on the associated solution for a linearly elastic material. Applying the hereditary integral in Equation (1) leads to the following time-dependent indentation depth under a prescribed arbitrary indentation loading history in a linearly viscoelastic material by a rigid spherical indenter with a radius $\mathrm{R}$

$h^{3 / 2}(t)=\frac{3(1-v)}{8 \sqrt{R}} \int_{0}^{t} J(t-\xi)\left[\frac{d P(\xi)}{d \xi}\right] d \xi$

where $J(t)$ is the creep compliance in shear at time.

If the indentation load is $P(t)=a_{0} t H(t)$, with $a_{0}$ being the loading rate and $H(t)$ the Heaviside unit step function. Substituting $P(t)$ into Equation (2), we have

$$
h^{3 / 2}(t)=\frac{3(1-v) a_{0}}{8 \sqrt{R}} \int_{0}^{t} J(t-\theta) d \theta
$$

The Kelvin model of viscoelastic $m$ aterial is used in our research, so th e general representation of the creep function based on the Kelvin model is

$J(t)=J_{0}+\sum_{i=1}^{N} J_{i}\left(1-e^{-t / \tau_{i}}\right)$,

where $\mathrm{J}_{0}, \mathrm{~J}_{1}, \cdots \mathrm{J}_{\mathrm{N}}$ are compliance numbers, $\tau$ ${ }_{1}, \tau_{2}, \cdots \tau_{\mathrm{N}}$ are retardation times, and $\mathrm{N}$ is a positive integer ${ }^{[9]}$. Substituting Equation (4) into Equation (3) leads to

$h^{3 / 2}(t)=\frac{3(1-v) a_{0}}{8 \sqrt{R}}\left[\left(J_{0}+\sum_{i=1}^{N} J_{i}\right) t-\sum_{i=1}^{N} J_{i} \tau_{i}\left(1-e^{-t / \tau_{i}}\right)\right]$

Since $\mathrm{P}(\mathrm{t})=\mathrm{a}_{0} \mathrm{t}$, Equation (5) can be rewritten as

$h^{3 / 2}(t)=\frac{3(1-\nu)}{8 \sqrt{R}}\left[\left(J_{0}+\sum_{i=1}^{N} J_{i}\right) P(t)-a_{0} \sum_{i=1}^{N} J_{i} \tau_{i}\left(1-e^{-P(t))\left(a_{0} \tau_{i}\right)}\right)\right](6)$

Therefore the creep function $\mathrm{J}(\mathrm{t})$ and the experimental data would be connected with Equation (6).

\section{EXPERIMENTAL PROCEDURES}

Experiments were performed using a Nano Test system with standard diamond spherical indenters $(\mathrm{R}=400$ micron), supplied by MicroMaterials Ltd., Wrexham, UK ${ }^{[10]}$. The 
sample of offset rubber blanket was cut to $30 \times$ $30 \mathrm{~mm}$ square shape and cleaned by pressure gas. All nanoindentation tests were performed at room temperature $23^{\circ} \mathrm{C}$ and humidity $50 \%$.

After the blanket samples were mounted in the indenter, controlled indentation load was applied $(\mathrm{P}(\mathrm{t})=0.01 \mathrm{t} \mathrm{mN})$, and the indentation load and indentation depth were recorded simultaneously. So we can get the load-displacement curve of the blanket sample.

Then we can fit Equation (6) into the load-displacement experimental curve to find a set of the best-fit parameters $\mathrm{J}_{0}, \mathrm{~J}_{1}, \cdots \mathrm{J}_{\mathrm{N}}$ and $\tau$ ${ }_{1}, \tau_{2}, \cdots \tau_{\mathrm{N}}$. And we can determine the creep function by substituting these parameters into Equation (3). In the experiment, two brands of offset rubber blankets were used which named blanket A and blanket $\mathrm{B}$ respectively.

\section{RESULTS AND DISCUSSION}

We fit the load-displacement experimental curves to Equation (6) to find the best-fit parameters. Fig .2 shows the fitted curves from indentation load-displacement curves obtained from experiment. The root mean square error (RMSE) of the fitted curve for blanket $A$ is 0.0002241 , and the RMSE of the fitted curve for blanket B is 0.001843 . For blanket A, the creep function obtained by substituting the best-fit parameters into Equation (3) is

$$
J(t)=298.5+301.5\left(1-e^{-t / 1.047}\right)+212.4\left(1-e^{-t / 1 / .880}\right)+283.2\left(1-e^{-t / 0.340}\right),
$$

Where $\mathrm{J}(\mathrm{t})$ is the creep compliance in shear in $1 / \mathrm{GPa}$ and $\mathrm{t}$ is time in second. For blanket $\mathrm{B}$, the creep function is

$$
J(t)=184.8+396\left(1-e^{-t / 0.99}\right)+0.02\left(1-e^{-t / 1 / .68}\right)+154.4\left(1-e^{-t / 1 / .00}\right) .
$$

These two creep functions are plotted in Fig .3.

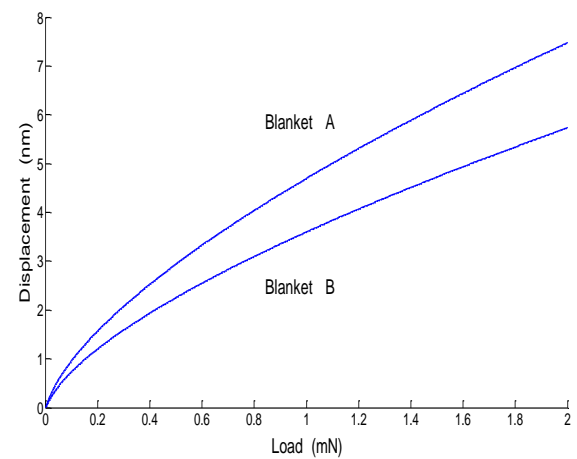

Figure 2. Fitted curves from indentation load-displacement data

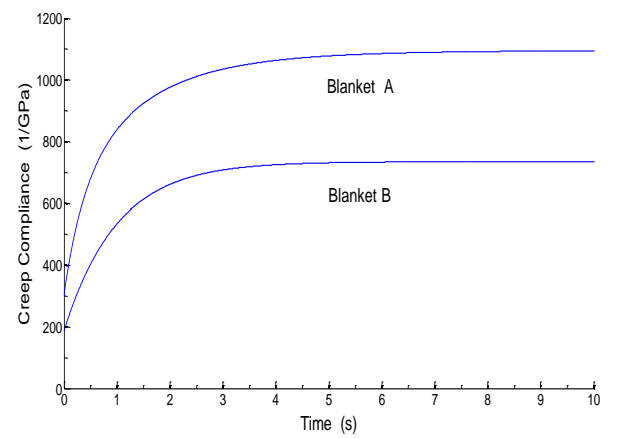

Figure 3. Creep function curves

It is shown from Fig . 2 and Fig . 3 that blanket A will get much displacement and react faster than blanket B does on the same load. In other words, an offset press with blanket A will transfer much thicker ink layer to paper than the same offset press with blanket B. This analysis result is consistent with the performance of these two brand blankets in actual printing activity. And we have used the creep function of blanket we obtained as noted in this paper into the study of offset precise ink transfer rule. The results show that the computer simulation calculation from the model considered the creep behavior of rubber blanket is more in line with the experimental performance of offset printing machine.

\section{CONClusions}

Nanoindentation experimental technique was used to study the viscoelastic behavior of offset blanket in the paper. In the study, the spherical indenter made of diamond is used. We induced the creep function formula of offset blanket in the 
experimental situation, fitted the experimental curves to the creep function formula and found the best-fit parameters to the creep function. The creep function of offset blanket obtained from this experimental method has contributed to the research on the precise ink transfer rule of offset press. The studies find that the viscoelastic creep behavior of rubber blanket is very important in getting the precise ink transfer rule in the research of offset press control technology.

\section{ACKNOWLEDGEMENT}

The authors acknowledge the financial support from the scientific research Program of education department of Shaanxi province

(Grant No. 14JK1528).

\section{REFERENCES}

[1] Heidelberger Druckmaschinen AG, 100 years of offset printing: innovations, markets, technology. 2008: 22.
[2] Helmut Kipphan, Handbook of print media: technologies and production methods. New York: Springer, 2006: 207-209.

[3] A. A. Elsharkawy, "Visco-elastohydrodynamic lubrication of line contacts," Wear, Vol. 199,1996, pp $45-53$.

[4] Hualong $\mathrm{Yu}, \mathrm{Zhe} \mathrm{Li}, \mathrm{Q}$. Jane Wang, "Viscoelastic-adhesive contact modeling: Application to the characterization of the viscoelastic behavior of materials," Mechanics of Materials, Vol. 60,2013, pp. 55-65.

[5] Kumar, M. V. R., and Narasimhan, R.,"Analysis of Spherical Indentation of Linear Viscoelastic Materials," Current Science, Vol.87, 2004,pp. 1088-1095

[6] Sneddon, I.N., "The relation between load and penetration in the axisymmetic boussinesq problem for a punch of arbitrary profile, "International Journal of Engineering and Science, 1965, pp. 47-57.

[7] Lee, E.H. and Radok, J.R.M., "A critical appraisal of the extraction of creep parameters from nanoindentation data obtained at room temperature, "Acta Materialia, Vol. 54,2006, pp. 5489-5499.

[8] Lee, E.H. and Radok, J.R.M., "The contact problem for viscoelastic bodies,"Journal of Applied Mechanics, Vol 27, 1960, pp. 438-444.

[9] Francesco MAINARD, and Giorgio SPADA, "Creep relaxation and viscosity properties for basic fractional models in rheology,'The European Physical Journal, Vol. 193, 2011,pp. 133-160.

[10] NanoTest system, manufactured by Micro materials Ltd. Wrexham, UK, 2009. 